\title{
Pkd1l1 as a molecular sensor of fluid flow during the breaking of left-right symmetry
}

\author{
DT Grimes, ${ }^{*}$ KL Riley, S Field, SH Patel, J Keynton, H Hilton, A Greenfield, DP Norris \\ From First International Cilia in Development and Disease Scientific Conference (2012) \\ London, UK. 16-18 May 2012
}

In mammals, left-right symmetry is broken during development by motile cilia-driven fluid flow in the embryonic node. How this 'nodal flow' is sensed remains the subject of debate. In kidney, fluid flow/membrane stress is sensed by polycystin protein complexes composed of Pkd1 and Pkd2 which reside in primary cilia. Pkd2 also plays a role in determining left-right asymmetry but no role has been found for Pkd1. We have isolated the ENU mouse mutant $r k s$ which harbours a mutation in the $P k d 1$-related gene Pkd1l1. Pkd1l1rks mutants exhibit severe left-right defects, loss of asymmetric gene expression but normal node cilia structure and motility. These data reveal the functional relationships between Pkd1 and Pkd1l1 which appear to be split between kidney development and left-right asymmetry respectively. Pkd2lrm4 mutants strongly phenocopy Pkd1l1rks embryos with severe left-right defects. Based on this, we hypothesise that Pkd111 and Pkd2 are both required for the sensation of nodal flow. In support, we find that Pkd111 localises to primary cilia in a Pkd2-dependent manner and that Pkd111 and Pkd2 can form physical associations. The Pkd1l1rks point mutation lies in an extracellular PKD domain, specifically implicating this domain in the establishment of left-right asymmetry. We are performing cell-based experiments to understand the mechanism of Pkd111 function as well as computational and biophysical assays to assess the nature of the PKD domain and how its structure and function are affected by the Pkd1l1rks mutation.

Published: 16 November 2012

* Correspondence: d.grimes@har.mrc.ac.uk MRC Harwell, UK

C 2012 Grimes et al; licensee BioMed Central Ltd. This is an Open Access article distributed under the terms of the Creative Commons Attribution License (http://creativecommons.org/licenses/by/2.0), which permits unrestricted use, distribution, and reproduction in any medium, provided the original work is properly cited.
doi:10.1186/2046-2530-1-S1-P68

Cite this article as: Grimes et al:: Pkd111 as a molecular sensor of fluid flow during the breaking of left-right symmetry. Cilia 2012 1(Suppl 1): P68.

Submit your next manuscript to BioMed Central and take full advantage of:

- Convenient online submission

- Thorough peer review

- No space constraints or color figure charges

- Immediate publication on acceptance

- Inclusion in PubMed, CAS, Scopus and Google Scholar

- Research which is freely available for redistribution \\ () Biolyed Central}

